\title{
Correction to: Religion Affects Future Female Doctors' Approach to HPV Vaccination in Czech and Slovak Republics
}

\author{
Jozef Zahumensky ${ }^{1}$ Petra Psenkova ${ }^{1}$ - Livia Melnikova ${ }^{1} \cdot$ Paula Drabiscakova ${ }^{1} \cdot$ Alexandra Nadzamova $^{1}$. \\ Marian Kacerovsky ${ }^{2} \cdot$ Ondrej Simetka $^{3} \cdot$ Erik Dosedla $^{4}$
}

Published online: 31 May 2021

(c) American Association for Cancer Education 2021

\section{Correction to: Journal of Cancer Education https://doi.org/10.1007/s13187-021-01995-3}

The original version of this article unfortunately contained a mistake. The name of the authors is now corrected in the author group.

The original article has been corrected.

Publisher's Note Springer Nature remains neutral with regard to jurisdictional claims in published maps and institutional affiliations.

The online version of the original article can be found at https:// doi.org/10.1007/s13187-021-01995-3.

Petra Psenkova

petrapsenkova@gmail.com

1 2nd Department of Gynecology and Obstetrics, University Hospital Bratislava and Comenius University, Ruzinovska 6, 82606 Bratislava, Slovakia

2 Department of Obstetrics and Gynecology, University Hospital Hradec Kralove, Sokolska 581, 50005 Hradec Kralove, Czech Republic

3 Department of Gynecology and Obstetrics, University Hospital Ostrava, 17. listopadu 1790/5, 70852 Ostrava, Czech Republic

4 Department of Obstetrics and Gynecology, Pavel Jozef Safarik University, Private Hospital Kosice-Saca Inc., 1stTrieda SNP 1, 04011 Kosice-Saca, Slovakia 